\title{
$\mathrm{Fe}-45 \% \mathrm{Cr}$ 合金の $\sigma$ 変態におよ㴗す $\mathrm{Ni}$ の影響*
}

$$
\text { 熊田健三 郎** }
$$

Kenzaburô Kumada : Effect of Nickel on the Sigma Transformation in $\mathrm{Fe}-45 \% \mathrm{Cr}$ Alloys. The effect of nickel on the sigma transformation in $\mathrm{Fe}-45 \% \mathrm{Cr}$ alloys, was studied by dilatometric, magnetic measurements and microscopic observations. Specimens were transformed into the sigma phase in the temperature range from $650^{\circ} \sim 800^{\circ} \mathrm{C}$ for various periods of time. It was established that the rate of the sigma transformation in $\mathrm{Fe}-\mathrm{Cr}$ alloys and the expansion coefficient of sigma increase with the increase of the nickel content up to $4 \%$. Some effects of nickel on physical and mechanical properties of ferrite of $\mathrm{Fe}-\mathrm{Cr}$ alloys were also studied.

(Received January 7, 1966)

\section{I. 錆产}

さに $25 \mathrm{Cr}-20 \mathrm{Ni}$ オーステナイト鋼の $\sigma$ 相生成への $\mathrm{A} 1$ の影幚について報告した(1)。それによると $\mathrm{A} 1$ 量が増加す ると溶体化温度より, 泠却後オーステナイトと共存するフ ニライト量が增加する，オーステナイトと共存するフェラ イト中には一般にフェライト生成元素がオーステナイト中 より濃化することが知られている(2)(3)，それ故，フェライ ト中に $\mathrm{Al}$ がかなりの量含まれることが期待されるのにこ のフェシイトが容易に $\sigma$ 相に変化する. 一方 $\mathrm{Fe}-\mathrm{Cr}$ 合金 の $\sigma$ 変態への Al の影響について報告された(4)(5)結果炕よ

** 東北大学金属材料研究所 (The Research Institute for Iron, Steel and Other Metals, Tohoku, University, Sendai)

* 1962 年 4 月本会東京大会比発表

(1) K.Kumada: 1957 年 4 月本会講演大会で発表

(2) T.P.Hoar and K. W. Bowen: Trans. ASM, 45 (1953) , 443

(3) H.T.Shirley: J.Iron Steel Inst., $174(1953), 242$.
ると， $\mathrm{Al}$ は Fe- $\mathrm{Cr}$ 合金の $\sigma$ 変態を抑制する．それ故，才 ーステナイトと共存するAl をかなり含有しているフェラ イトが，容易に $\sigma$ 化する原因として，共存するオステーナ イトの影響, フェライト中にかなり含有されている Ni の 影響が考号られる・鉄ークロム合金の。変態への Ni の影 響については明らかでない，それ故本研究ではの変態速度 が早い $45 \% \mathrm{Cr}-\mathrm{Fe}$ 合金に Ni 4\% 要で添加したときの， $\sigma$ 変熊への Ni の影響を調べた。

\section{II. 試 料 の 調 製}

素材として電解鉄，低炭素つェロクロムを用い，Ni の添 加には電解 Ni を用いた。溶解は高周波誘導炉で大気中溶 解を行ない約 $25 \mathrm{~mm}^{2}$ の角型銅塊 $2 \mathrm{~kg}$ を溶製し $\phi 7 \mathrm{~mm}$ の 丸棒に鍛造し，これより $\phi 5 \mathrm{~mm}$ ，長さ $70 \mathrm{~mm}$ の丸棒試料

（4）K.Kumada：1956 年 10 月本会講演大会で発表

(5) M. Tagaya and S. Nenno: Tech. Repts. Osaka Univ., 5(1955), 149 . 
を旋削什上げし， $1000^{\circ} \mathrm{C} 2 \mathrm{hr}$ 暁鈍後， $900^{\circ} \mathrm{C}$ 上り水椧し て実験に用いた。用いた陚料の化学成分を Table 1 亿示 している.

Table 1 Chemical analyses of specimens.

\begin{tabular}{|c|c|c|c|c|c|c|c|}
\hline \multirow{2}{*}{$\begin{array}{l}\text { Mark of } \\
\text { specimen }\end{array}$} & \multicolumn{4}{|c|}{ Composition } & \multicolumn{3}{|c|}{ (\%) } \\
\hline & C & $\mathrm{Si}$ & $\mathrm{Mn}$ & $\mathrm{Cr}$ & $\mathrm{Ni}$ & $\mathrm{Al}$ & $\mathrm{N}$ \\
\hline & 0.074 & 0.69 & 0.24 & 43.50 & 0.20 & 0.041 & 0.071 \\
\hline $\mathrm{CN}$ & 0.071 & 0.63 & 0.36 & 43.54 & 0.73 & 0.033 & 0.0 \\
\hline & 0.078 & 0. & 0. & 43 & 1.27 & 0. & 0. \\
\hline & 0.076 & 0.45 & 0.23 & 43.54 & 2.21 & 0.036 & 0.091 \\
\hline $\mathrm{Cl}$ & 0.083 & 0.55 & 0.43 & 43.74 & 4.17 & 0.022 & 0.082 \\
\hline & 0.0 & 0.49 & 0.37 & 47 & 4.34 & 0.030 & 0.11 \\
\hline CN $40-4$ & 0.069 & 0.39 & 0.35 & 38.63 & 3.95 & 0.021 & 0.072 \\
\hline
\end{tabular}

\section{III. 実 験 方 法}

熱膨張計に装置した試料を真空中で急速加熱し，所定燒 鈍温度に達した後の $\sigma$ 相への变態を試料の長さ变化によつ て測定した。宽鈍温度は $650^{\circ}, 700^{\circ}, 750^{\circ}$ と $800^{\circ} \mathrm{C}$ とし た.試料の長さ変化がなくなるまで所定温度に保持した後 炉冷した．この完全に $\sigma$ 相になつた試料の加熱膨張曲線を 求め, $\sigma$ 相の熱膨張係数と $\sigma \rightarrow \alpha$ 変熊温度への Ni の影響を 調べた. 加熱速度は $10^{\circ} \mathrm{C} / 3 \mathrm{~min}$ である. その他 $\mathrm{Fe}-\mathrm{Cr}$ 合金の硬度，磁化の大いさ打よび顕攽鏡組織への Ni の影 響をも調べた。

\section{IV. 実験結果と考察}

\section{1. 变龍曲線}

$650^{\circ}, 700^{\circ}, 750^{\circ}, 800^{\circ} \mathrm{C}$ の各温度で $\sigma$ 变態に伴な5収 縮と保持時間との関係を求めた一例として, $700^{\circ} \mathrm{C}$ と 800 ${ }^{\circ} \mathrm{C}$ の結果を Fig. 1 亿示して市る. 参考のために Ni 4\%を 含んだ $\mathrm{Cr} 40 \%$ ，50\% の結果をも併示してある. 図に見る よ5に, Ni 量の增加とともに $\sigma$ 変態が早くなつている. 各 々の焼鈍温度での变態曲線より変態開始, 終了に要する時 間を求めて, 焼鈍温度と，また $\mathrm{Ni}$ 量との関係を示したるの が Fig.2 (a)，(b)である. 潜伏，終了時間は曲線とそ礼に 接する水平線との交点をとつた. Fig.2 (a) $の \sigma$ 相の恒温変態曲線でC 型曲線を示すことはすで報告 されている(6)(7). 図より $\mathrm{Ni}$ 量が增すと $\sigma$ 変態の潜伏，終 了時間の両方とるに減少していることが判る.しかし，C 曲線を単に時間の短い左方に平行に移すのではなく, $\mathrm{Ni}$ 量 が $1 \%$ 以上になると $800^{\circ} \mathrm{C}$ での変態終了，潜伏両時間が $750^{\circ} \mathrm{C}$ に捄るよりる小さくなつている。単味の Fe-Cr 合 金の $\sigma$ 変態の最む早い温度は $750^{\circ} \mathrm{C}$ 付近にあるので, $\mathrm{Ni}$ $1 \%$ 以上の添加は $\sigma$ 变態の最す早い温度を上年することを 示している. Fig. $2\langle$ b $)$ より $\sigma$ 変態終了, 潜伏時間の両方と も Ni $2 \%$ をでは急速に減少するが Ni $2 \%$ 以上では減少の

(6) E. Baerlecken und H. Fabritius: Arch. Eisenhütt., 26 (1955), 679 .

(7) G.F.Tisinai, J.K.Stanley and C.H.Samans : J. Metals, 8(1956), 600 .



Fig.1 Effect of nickel on the rate of sigma transformation in $\mathrm{Fe}-\mathrm{Cr}$ alloys.

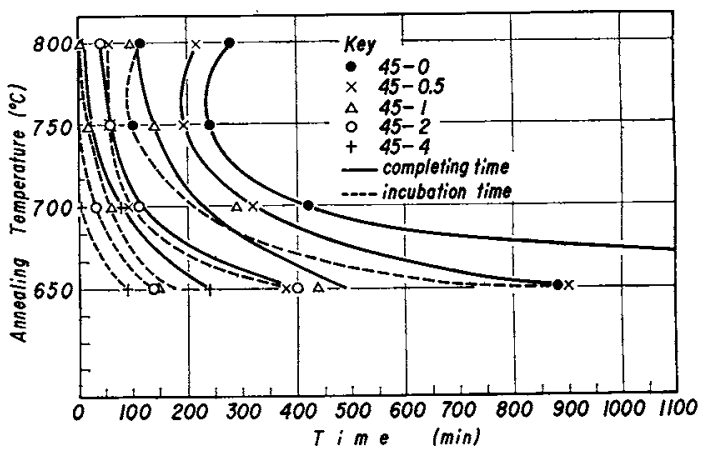

Fig. 2 (a) Relations between annealing temperatures and completing and incubation times of the sigma transformation in $\mathrm{Fe}-45 \% \mathrm{Cr}$ alloys.

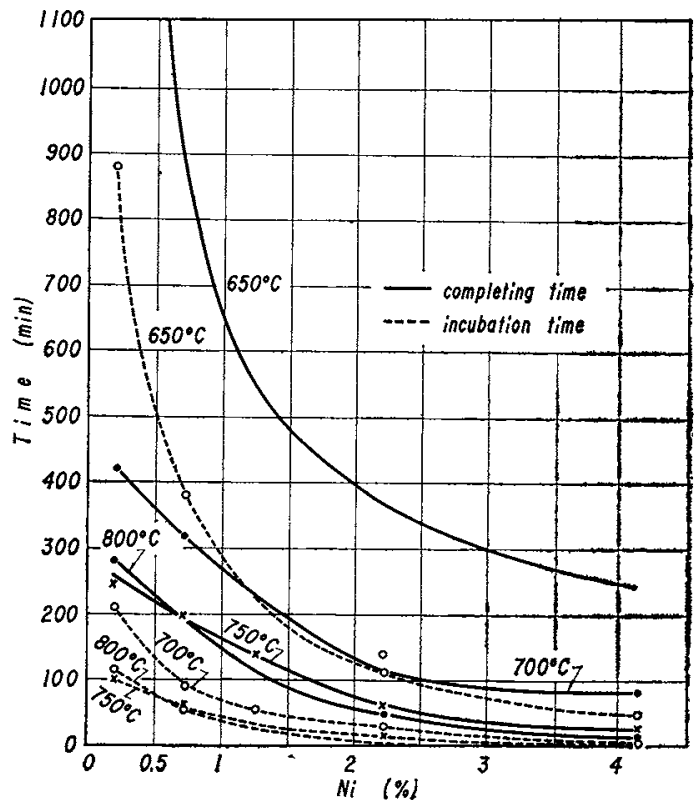

Fig. 2(b) Effects of nickel on the completing and incubation times of sigma transformation in $\mathrm{Fe}-45 \% \mathrm{Cr}$ alloys. 
程度はそれほど著しくないことが判る。変態に伴なう収 縮量を，そのときの試料長さの百分率で表わし $\mathrm{Ni}$ 量との

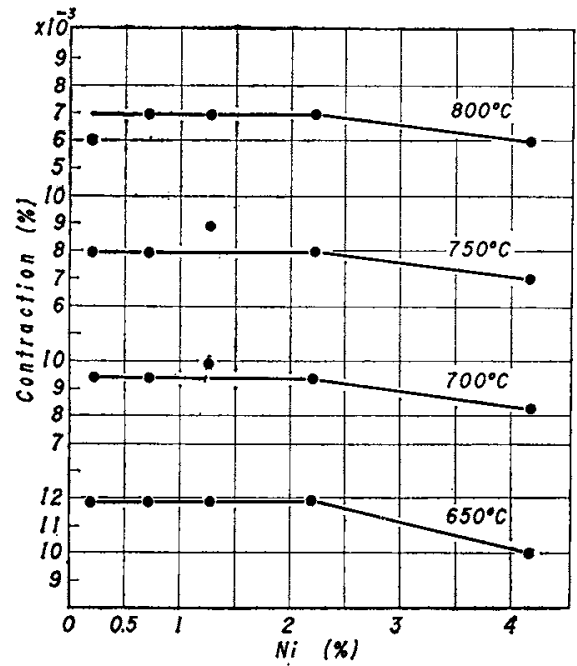

Fig.3 (a) Effect of nickel on the contraction through the sigma transformation at indicated temperatures.

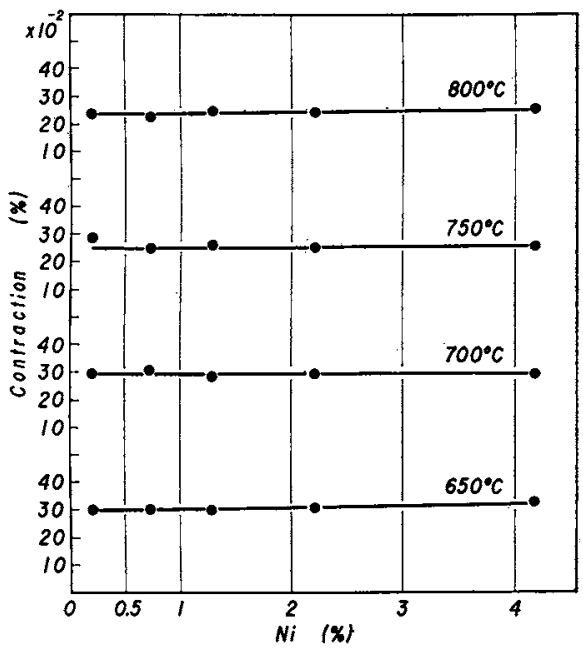

Fig.3 (b) Effect of nickel on the contraction through the sigma transformation at room temperature.

関保を Fig.3(a) に示している.Ni 量の増加は収縮量を減 少する傾向が見られる，常温での収縮量と Ni 量の関係を Fig.3 (b) に示している.Ni 量による收縮量の変化は活とん ど見られない。

\section{2. 熱 脚 張}

上記の実験で兄られた $\sigma 1$ 相試料について約 $10^{\circ} \mathrm{C} / 3 \mathrm{~min}$ の加熱速度で， $1000^{\circ} \mathrm{C}$ まで熱膨張を測定した. $1000^{\circ} \mathrm{C}$ ま で加熱すると $\sigma \rightarrow \alpha$ 復元変熊が完了する.これら曲線より 常温から 各温度間の 平均熱膨張 係数を算出し Fig. 4 (a) に 示してある. 参考のため $1000^{\circ} \mathrm{C}$ 加熱後 $900^{\circ} \mathrm{C}$ 上り水冷し
たフェライトの平均熱膨張係数をる示してある。因に見る 上うに両者ともに Ni 量の增加とともに增加の傾向が見ら

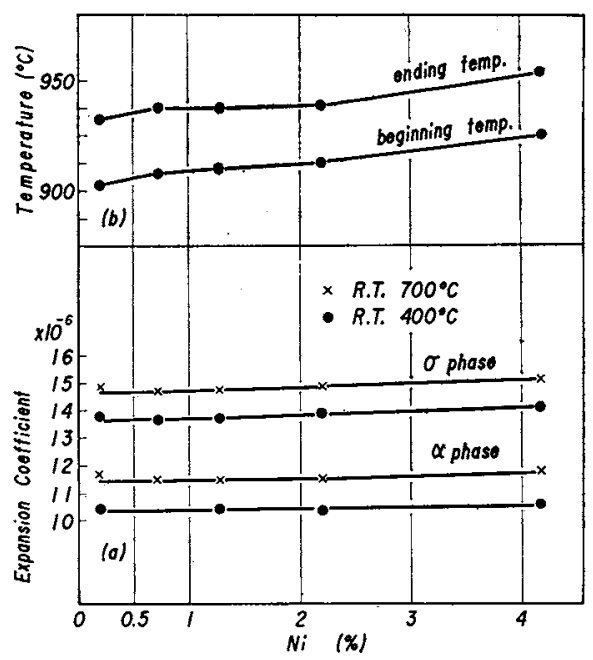

Fig.4 Effect of nickel on the thermal expension coefficient of sigma and alpha phase (a) and on the temperature of sigma to alpha transformation in $\mathrm{Fe}-\mathrm{Cr}$ alloys (b)

れる. $\sigma \rightarrow \alpha$ 復元変態に伴なら膨張が急にはじまる温度と 終了した温度とを $\mathrm{Ni}$ 量によって示したのが Fig.4 (b)であ る. $\mathrm{Ni}$ 量の增加とともに高温汇䔟動しているのが判る.

\section{3. フェライトヘの $\mathrm{Ni} の$ 影篦}

$\mathrm{Fe}-\mathrm{Cr}$ 合金のフェライトの性質への $\mathrm{Ni}$ の影響を磁気 的珄質と，硬度について調べた結果を Fig.5 に示してあ

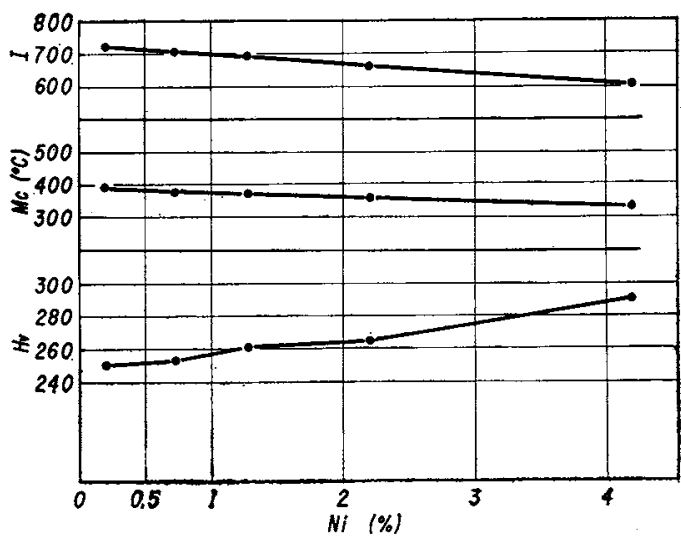

Fig.5 Effect of nickel on the hardness, magnetic transformation temperature and intensity of magnetization in $\mathrm{Fe}-\mathrm{Cr}$ alloys, water quenched from $900^{\circ} \mathrm{C}$ after annealing at $1000^{\circ} \mathrm{C}$ for one hour.

る. $1000 \mathrm{Oe}$ の有效磁場での磁化の大いさ $I$ と磁気变態点 $\mathrm{Mc}$ は $\mathrm{Ni}$ 量の堌加とともに減少しているのが見られる.硬 度は $\mathrm{Ni}$ 量の增加ととも增大していることが判る。

\section{4. 顥微 鏡 組}

$1000^{\circ} \mathrm{C}$ 焼鈍 $900^{\circ} \mathrm{C}$ より水冷した 試料の組織を Photo. 1 
に示してある．腐食剤は 1 容の王水 $+1 / 2$ 容グリセリンを＼cjkstart認めうるほどの $\sigma$ 相は存在しない，焼鈍時間が長くなるに 用いた。主として炭化物と見られる粒状相が見られフェラつつれて $\mathrm{Ni}$ 量とともに $\sigma$ 相の生成量が多くなつている.700
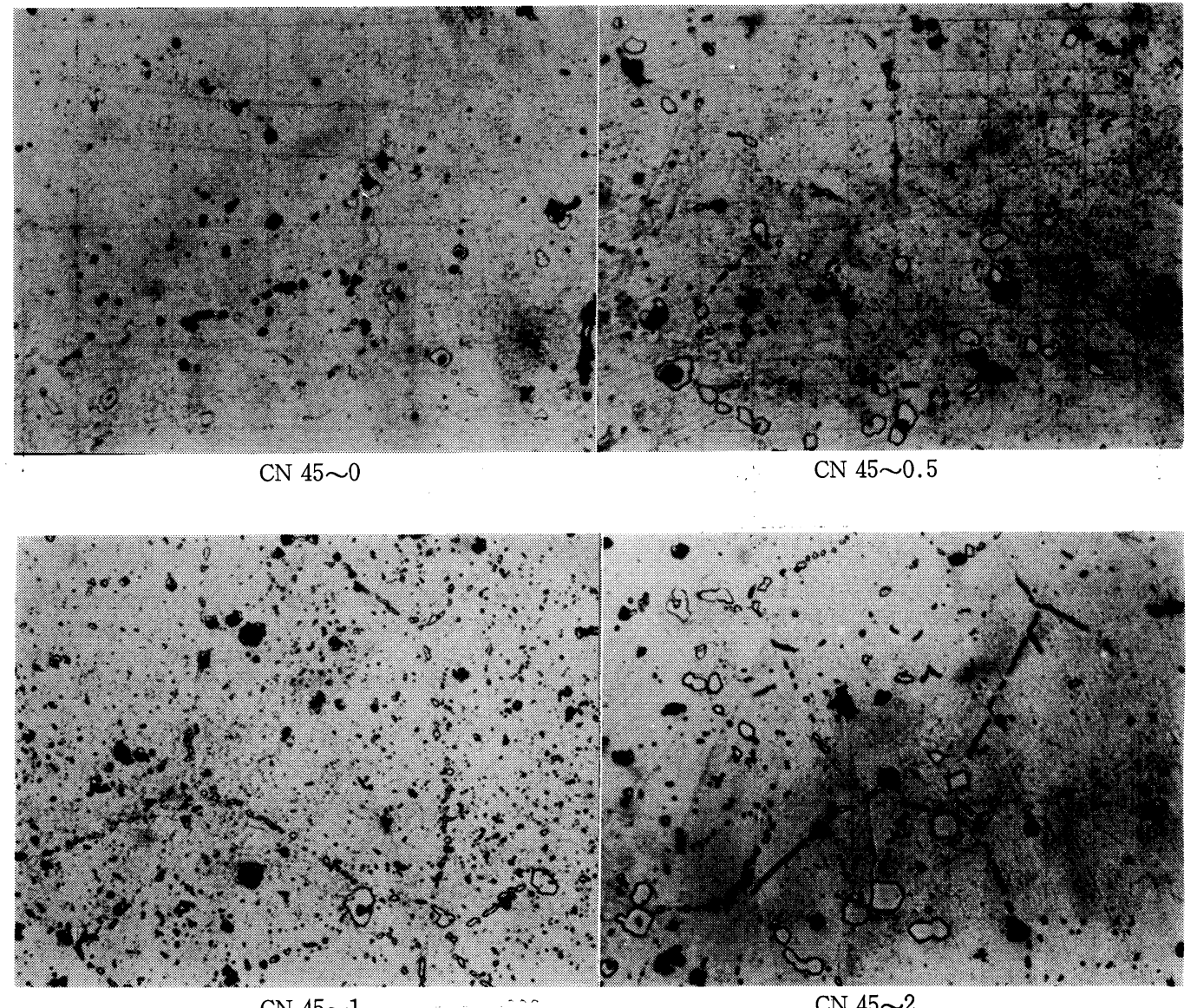

$\mathrm{CN} 45 \sim 1$

$\mathrm{CN} 45 \sim 2$

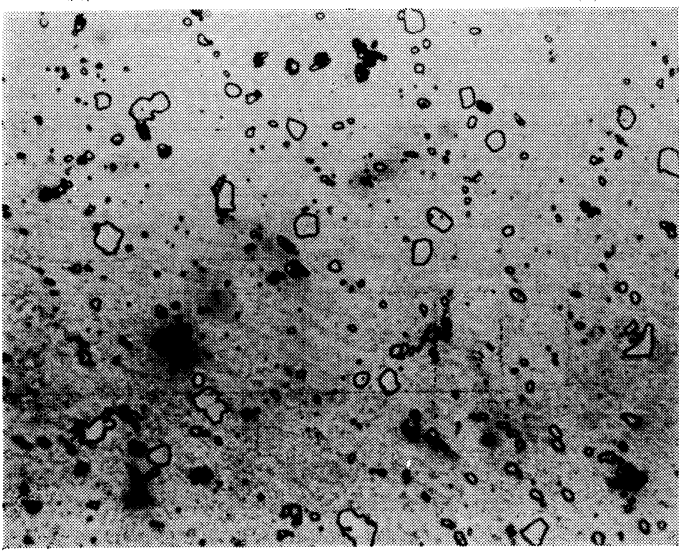

$\mathrm{CN} 45 \sim 4$
Photo.1 Microstructures of CN 45 series specimens water quenched from $900^{\circ} \mathrm{C}$ after holding at $1000^{\circ} \mathrm{C}$ for one hour. $\quad(\times 400)$
イトの結晶粒界は焼鈍した試料に比して少しく表われ難 い. $700^{\circ} \mathrm{C} 1 \mathrm{hr}$ 焼鈍 したときの組織をPhoto. 2 に示して いる. $4 \% \mathrm{Ni}$ 試料は完全に $\boldsymbol{\sigma}$ 相に変態し非磁性となつて いることを確めた． $2 \% \mathrm{Ni}$ 試料にもかなりの量の $\sigma$ 相が 生成しているのが見られる.Ni1\% 以下の試料では明瞭に
${ }^{\circ} \mathrm{C}$ で $5 \mathrm{hr}$ まで焼鈍したときの各燒鈍時間ごとに測定した 硬度と焼鈍時間の関係を各 くの試料について Fig. 6 に示し ている。 $\sigma$ 相の硬度が大きいため $\sigma$ 相が生成すると硬度が 增加する。 $\sigma$ 相とフェライトが共存すると硬度は均一でな いので硬度として最低值と最高値の 2 つを示してある。 
変態の早いNi の多い試料では硬度の増加が短時間内で著

しいが $\mathrm{Ni}$ を添加しない陚料では $700^{\circ} \mathrm{C}, 5 \mathrm{hr}$ 燒銛後も硬
変態を促進する $\mathrm{Ni}$ の影響が $\mathrm{Ni}$ 何\%をで存在するかはい まりところ確実にいいらるデーターがないが，とにかく

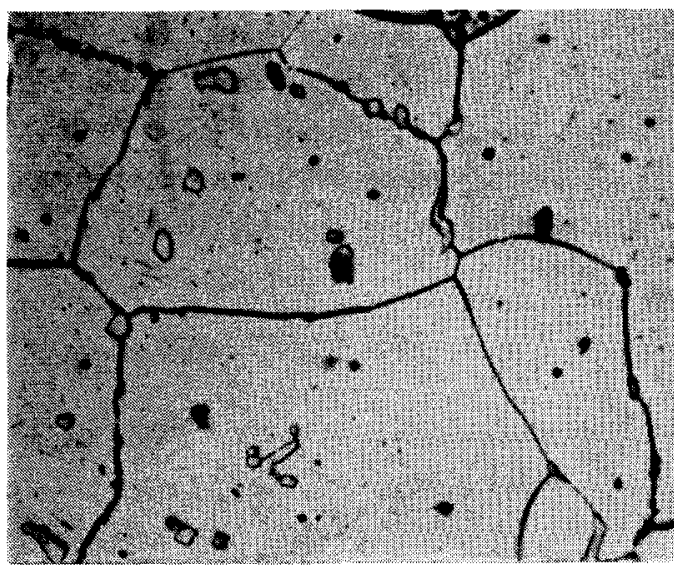

$\mathrm{CN} 45 \sim 0$

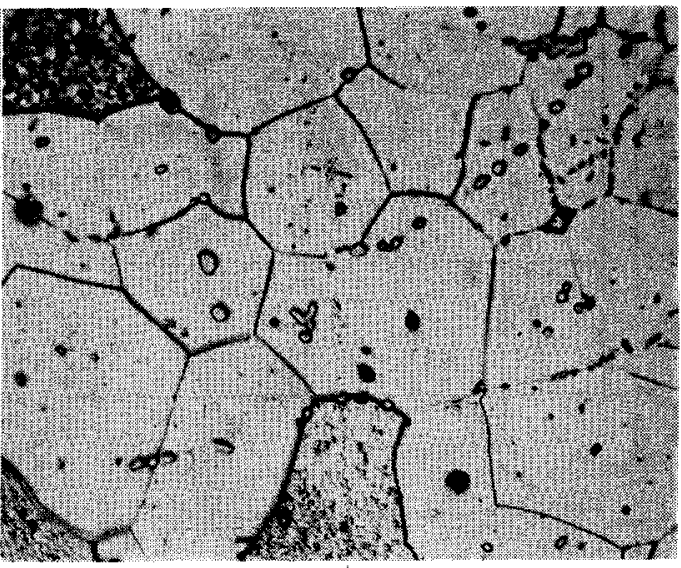

$\mathrm{CN} 45 \sim 0.5$

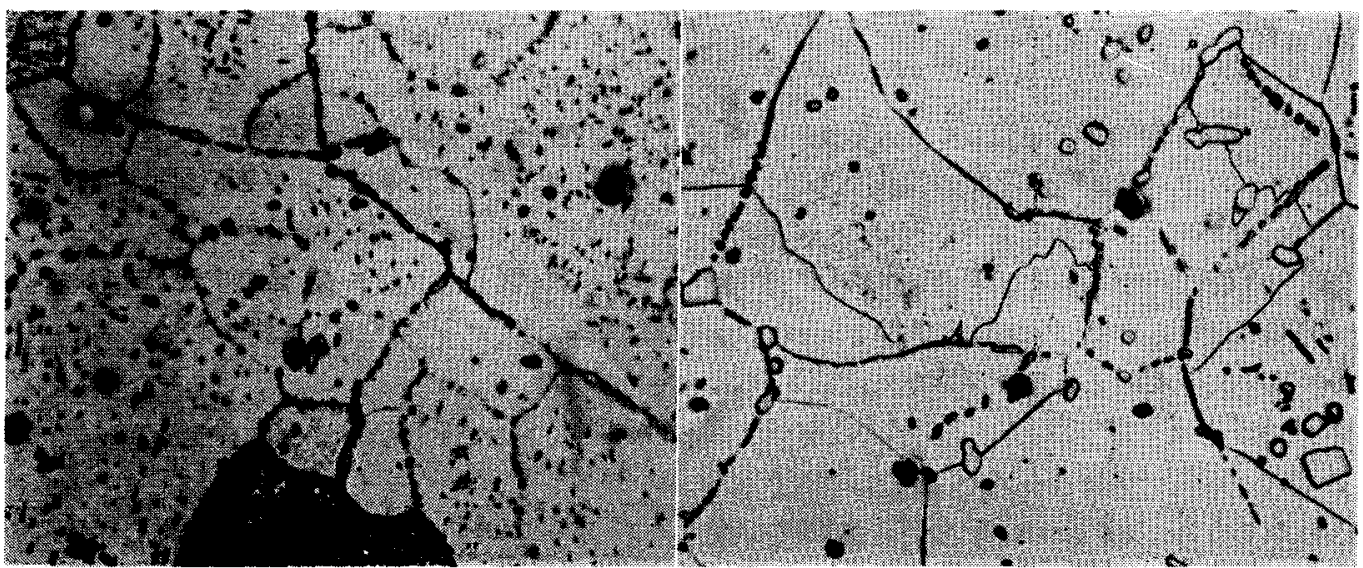

CN $45 \sim 1$

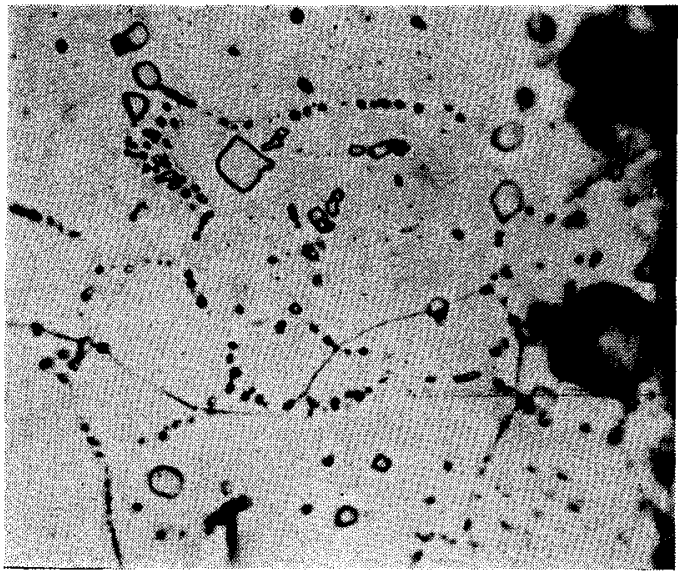

CN 45 1
Photo.2 Microstructures of the same specimens as those shown in Photo.1, annealed at $700^{\circ} \mathrm{C}$ for one hour. $\quad(\times 400)$
度の增加ま余り見られない。

Figs.1，2 より明らかなように, $\mathrm{Ni}$ 量が增加するにつれ て。変態が早くなっている。このように Fe- $\mathrm{Cr}$ 合金の $\sigma$
奻 $\sigma$ 変態の潜伏，終了時間の両者を減少する効果が見られ る. そしてこの効果は $\mathrm{Ni}$ 量の少量添加の場合また燒鈯温 度の低いとき著しい，本研究で見られる $\mathrm{Ni} の \sigma$ 変態促進 
効果には各試料に含まれている約 $0.6 \%$ 程度の $\mathrm{Si}$ 効果む また含まれていることはいうまですないが，旮の効果は相

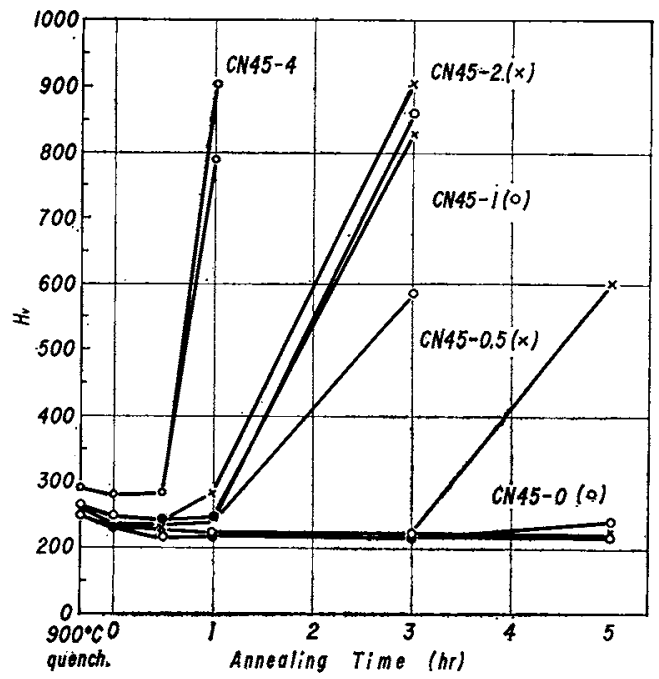

Fig. 6 Effect of annealing times on the hardness of $\mathrm{Fe}-\mathrm{Cr}$ alloys, annealed at $700^{\circ} \mathrm{C}$.

互に帖消しになる故 Ni の影響を見るにはさしつかえない と思われるが，Si の影響は Fig.2 (a)の 45-0 曲線の鼻の温 度より明らかである。単味の本試料程度の $\mathrm{Cr}$ を有する $\mathrm{Fe}-\mathrm{Cr}$ 合金の恒温变態のC曲線の 鼻は大体 $750^{\circ} \mathrm{C}$ 付近に

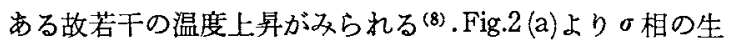
成温度範囲が $\mathrm{Ni}$ 量の增加とともに高温に移ることが判る。 $\mathrm{Ni}$ 量の増加とともに $\sigma$ 変態に伴なう収縮量が高温で減少 の傾向を示し，常温ではほとんど变化がないのは（Fig.3 (a) (b)) Ni ののとフェライトへの熱膨張保数の影響を示す

(8) K.Kumada：1962 年 4 月本会講演大会で発表
Fig.4(a)より了解しうる， $\sigma \rightarrow \alpha$ 復元変態温度を示す Fig.4 (b) の結果は上記のよ5に $\sigma$ 相の生成温度範用が $\mathrm{Ni}$ 量の增 加により高温に移動した結果によるるのであるが，これは $\sim 10^{\circ} \mathrm{C} / 3 \mathrm{~min}$ の加熱速度で得られた結果であるので, 平 衡状態の温度はかなり低温度㳊りまた Si のないとき はさらに低温度にあるであろ5．Fig.5の Fe-Cr 合金のフ エライトの硬度への Ni の効果はオーステナイトの硬度へ

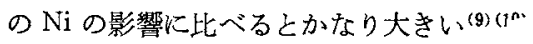

\section{V. 括}

約 $45 \% \mathrm{Cr}-\mathrm{Fe}$ 合金に $\mathrm{Ni}$ を\% まで添加したときの $\sigma$ 变態への Ni の影響と，これらの合金のフェライトの性質 への Ni の影響を熱膨張, 磁気, 組織について調べた結果 つぎのことが明らかになつた。

(1) $\mathrm{Ni}$ 量の增加ととむに Fe-Cr 合金の $\sigma$ 相変態の潜伏 時間, 終了時間の両方を短縮して $\boldsymbol{\sigma}$ 変態を促進する.

(2) $\mathrm{Ni}$ 量の堌加とともに $\sigma$ 変態に伴な 5 収縮量は高温 で減少し常温では汪とんど变化がない。

(3) $\mathrm{Fe}-\mathrm{Cr}$ 合金の $\sigma$ とフェライトの熱膨張係数は $\mathrm{Ni}$ 量 の増加とともに增加の傾向を示す。

(4) $\mathrm{Fe}-\mathrm{Cr}$ 合金フェライトの硬度は $\mathrm{Ni}$ 量とともに增加 乙磁気変態点は $\mathrm{Ni}$ 量とともに減少する.

本研究を行ならに当り指導をいただいた今井教授ならび にいろいろのご配虑をいただいた東北大学金属材料研究所 の職員の方々に深く感謝の意を表わしたい。

(9) K.J.Irvine, D.T. Llewellyn and F.B.Pickering: J.Iron Steel Inst., 199(1961), 153.

(10) K.Kumada：1961 年 4 月本会講演大会で発表 